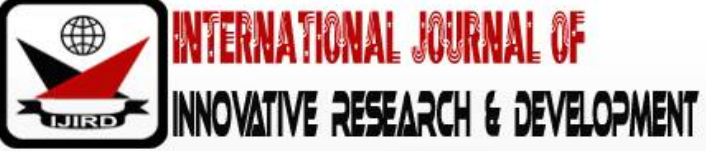

ISSN 2278 - 0211 (Online)

\section{Extent of Ward Schools' Compliance with the 2014 Education Policy Guidelines on Parental Involvement in Rukwa Region, Tanzania}

\author{
Dr. Ndasi Apolinary Kaswala \\ Lecturer, Archbishop Mihayo University College of Tabora (AMUCTA), Tanzania
}

\begin{abstract}
:
This study intended to assess the implementation of parental involvement inward schools in Rukwa region - Tanzania, based on the 2014 education policy. Tanzania's government has introduced education policy, requiring more active parental involvement in decisions and in resolutions for school development for ensuring their legitimation, financial accountability and to initiate voluntary contributions needed in schools. These roles invited questions for their implementation, being the first-time parental involvement was amplified in Tanzania, while there were challenges of parents' involvement in Rukwa region and contrary findings on parents' involvement. Concurrent parallel mixed methods design was employed using interview guides and questionnaires to 365 participants. The instruments were validated by five experts from MWEOAU faculty of education. Reliability was done by Cronbach alpha test for quantitative data but for qualitative data, conformability, credibility; dependability and transferability were ascertained. Quantitative data was analyzed by descriptive and inferential statistics and qualitative data through transcriptions, coding, categorizing themes and summarizing responses. The study found low extent of compliance with policy guidelines in ward schools. The study recommends to take concerted but professional action to mobilize parents to support the schools and school heads and teachers to adhere to the policy guidelines for adequate policy implementation.
\end{abstract}

Keywords: Compliance, decisions, education policy, guidelines, involvement

\section{Introduction}

Research has shown that parental involvement in schools, through decision making, and subsequently actively participating in implementation of education plans like supporting teachers, advising students, paying school fees, making voluntary contributions, among others, do contribute to school improvement (Rajabu, 2011; McNeal, 2014; Glanfiel, Ngalawa \& Simmt, 2015; United Republic of Tanzania - \{URT\}, 2015). They include high level of school attendance rate of learners, development of physical facilities and high academic achievement, among others (Dwyer \& Hecht, 1992).

However, the extent of parental involvement in the governance of schools in Tanzania, like in many other countries, had been low. It has adversely affected education quality due to parental un-involvement related factors such as students' truancy, dropout from school, indiscipline, shortage of human and material resources and others, and subsequent learners' poor academic achievement in the country (Maendaenda, 2010; URT - BEST, 2014; Nyandwi, 2014; Masue, 2014; URT, 2015). This has raisedstakeholders' concerns on the need to advance parental involvement in schools for educational improvement (Bernard, 2004; Focus, 2010; Magava, 2015, Kalolo, 2016).

As an intervention strategy, the government released the policy to address the said challenges. The 2014 Education Policy, through circular number 3 of 2016, and procedure for voluntary contributions in schools (URT, 2016 a \& b), had amplified parental involvement in schools in the country. For the first time, in the history of educationalpolicies in Tanzania, the government has widened parental involvement in decision making and resolutions in all public schools for ensuring legitimation of decisions and accountability there in.

While earlier efforts limited parents to attending parental meetings and making occasional contributions, the policy released by the Ministry of Education, Science and Technology in 2014, commissions parents to do more. They include holding the school management to account in case they contravene the education policy, ensuring legitimationof decisions in school administration, partaking in major resolutions in all public schools and holding teachers to account for secondary school failures to comply with the Education Policy and to be the initiators of voluntary contributions to solve challenges in schools (ibid.). These were new responsibilities to parents as well as new policy approaches to parents' involvement. Yet it was yet to be seen whether it scaled up parental involvement

Hence, stakeholders were debating the implementation of the 2014 Education Policy. Some holding that then parents were actively involved and others standing for the view that they were uninvolved. Others held that it had negatively affected school - community relationships while others believed it had improved it (Siyame, 2016 b; Hakielimu, 2017). These mixed views were inviting questions as to what extent the ward schools complied with the policy guidelines. In some parts of the country, the parents had resisted to contribute food for their children in schools, while the policy 
directed them to contribute (Siyame, 2016 b; Ismail, 2017). This was inviting questions with regards to parents' degree of involving in schools based on the policy.

Studies had indicated that some ward school heads involved parents in decision making and others not. While some studies reported high parental involvement in the governance of the schools (Salema, 2009; Fanuel, 2015; Glanfield, Ngalawa \& Simmt, 2015), others informed on low or un-involvement (Matekere, 2003; Bernard, 2004; Kalolo, 2016) and some others mixed findings in single studies. For instance, Makenya (2013) reported that parents participated in School Governing Boards (SGBs) and linked others to schools, but a quarter (25.4\%) of participants indicated parents being reluctant to involve in school activities as they were not aware of its importance for school management. This situation was begging a question as to why contrary findings on parental involvement in ward schools in the country and whether the schools could comply with the policy guidelines on parental involvement in the area of study.

The 2014 Education Policy Guidelines had created high expectations and interests of education stakeholders in the country. The driving force for underscoring parental involvement by the 2014 Education Policy was the need to address the challenges experienced in the past education policies as identified in their evaluation. The challenges included weak education supervision and management, lack of sufficient parental involvement and other stakeholders, shortage of teaching and learning resources, un-attractive teaching and learning environment, students' school dropout and subsequent poor learners' academic performance, among others (URT, 2014).

The aim of the 2014 education policy is to enhance efficient school supervision and management through more parental involvement, among others (URT, 2014-part 3 section 2). The policy emphasizes on the need to improve school leadership, school inspection, control, evaluation and authenticity by relevant authorities so as to scale up quality education.

However, it was unclear as to whether parents were motivated by the guidelines and were involving in schools as required. Literature indicates that the level of compliance with education policy provisions on parents' participation in schools had been low for varied reasons, including lack of clear understanding. Oyeniran (2017) reported parents being passive to school matters besides that the basic education in Ivory Coast was free. Nudzor (2013) found that the Free Compulsory Universal Basic Education (FCUBE) policy in Ghana was not clear to stakeholders including parents and that it remained a challenge. This view is echoed by Mualuko and Limukii (2012) who reported on parents' lack of clear understanding of fees free education policy and that it hindered their participation in the policy implementation in Kenya.Whether the Tanzania 2014 Education Policy Guidelines would make a difference from such experiences, was yet to be seen.

It was not known also whether the heads of schools and the teachers were ready to implement the policy guidelines for scaling up parental involvement including being held accountable by parents. These seemed potentially inhibitive of involving parents to a large extent and hence, jeopardizedeffective implementation of the policy guidelines.In Tanzania the school leadership styles and the legal framework had been set backs to high level parental involvement and so fixing their involvement to a low degree (URT, 1995 \& 2001; Kapela, 2012; Zahara, 2014; Kalolo, 2016). This trend was inviting questions on whether the 2014 Education Policy would make changes.

\subsection{Statement of the Problem}

While parental involvement in schools contributes to education improvement (Rajabu, 2011; McNeal, 2014; Glanfiel, Ngalawa \& Simmt, 2015), yet stakeholders have been questioning the efficacy of parental involvement in secondary schools in Tanzania, indicating concerns on the slim chance given to parents to adequately play their roles in managing public schools (Kalolo, 2016; Makwinya and Komba, 2014, Magava, 2015). This was a stumbling block to efficient management of the schools. Additionally, there were contrary findings on parents' involvement in schools in Tanzania; high involvement (Salema, 2009 and Fanuel, 2015); low involvement (Makwinya and Komba, 2014) and mixed levels(Makenya, 2013). Even after the government intervention, through the policy guidelines on more parental involvement in schools' management for enhanced accountability, stakeholders were still debating implementability, implying uncertainty for achieving government objectives (Kapinga, 2016; Hakielimu, 2017; Chawe, 2017). All the more, Rukwa region had exhibited unique challenges of parental involvement in schools that seemed jeopardizing the application of the policy guidelines (Mshani, 2015; Siyame, 2016 a \& c; URT, 2016; Yassin, 2017). Whether the policy was implemented and government objectives achieved in Rukwa region was unknown while literature was silent on the same. This study, therefore, examined the extent of ward schools' compliance with the 2014 Education Policy Guidelines on parental involvement in Rukwa region, Tanzania.

\subsection{Research Question and Hypotheses}

The study answered one question that asked: To what extent do ward schools in Rukwa region comply with policy guidelines on parental involvement? The study tested the following null hypotheses:

- There is no significant difference in the mean rating scores of school heads on the extent of implementation of the policy guidelines on parental involvement in decision making in ward schools in Rukwa region based on school location.

- There is no significant difference in the school heads' mean rating scores on the extent of implementation of the policy guidelines on parental involvement in decision making in ward schools in Rukwa region based on education level and work experience.

- There is no significant difference in the mean scores of teachers on parents' participation in decision making in ward schools in Rukwa region when compared with rural and municipal areas. 


\subsection{Theoretical Framework}

The study was grounded on Epstein's (1995) sixth types of parental involvement with special focus on the fifth type of taking part decision making. The theory is meant to facilitate parents/ family - school partnership or collective effort for enhancing effective education to children. The six types include parenting, communicating, volunteering, learning at home, decision making and collaborating with community.

By parenting, Epstein (1995) means parents' assistance to create conducive home environment for their children learning at home. They include families' provision of needed materials for children's learning at home, monitoringand assisting their children to accomplish their homework and planning for learning at home and communicating with schools. These help parents to participate in the institutions. Volunteering refers to parents' direct support in teaching and learning process and in the management of students. Decision-making, a fifth type of parental involvement, includes families participating in school decision making processes through parental meetings, parents' committees and improvement teams among others. Collaborating with community includes various activities through which parents liaise with community support and services to the learning of children. It is grounded on community resources for learning at school and at home. It entails creating awareness to students and families on various community resources for children's learning.

\subsubsection{Strengths of the Six Types of Involvement}

Parenting is relevant in the sense that it is the basis for parental involvement. In the policy of fees free basic education, parents were given tasks of providing basic education necessities of their children's education such as provision of text and exercise books for curriculum needs and paying fare to and from schools and health costs of their children. These help students learn at home and do their homework. In this sense, the theory applies to this study. Home-school communication applies to this study as the policy emphasised that the heads of schools must communicate and discuss school maters with parents. Aspects such as providing lunch for students and hiring part-time teachers among others, required clear communication between parents and schools. Students were to communicate with parents and give them feedback on school issues so that parents could assist them. Circular 3 directed students to give parents feedback on all that they were directed to do by schools so as to make parents actively involved in matters of school development (URT, 2016, part 3.9 sections iii \& iv). Any form of communication helps effect such involvement. This was quite applicable to this study.

Epstein's third type of parental involvement concerns with parents' direct support in teaching and learning process in classrooms and in students' management. It matches with the policy that directed parents to initiate and make voluntary contributions to cater for lunch, employing part-time teachers, security guards, costs for extension of class teaching/ learning hours, and the general school development. Though they did not teach in the classroom directly as the theory proposes, through their voluntary contributions, they assisted in improving classroom teaching and learning processes by purchasing the required teaching and learning resources. The type is thus relevant to the policy and, therefore, applicable to this study.

In this study, the main focus was on decision making as a fifth type as theorized by Epstein. Decision-making was the focus of the study. As earlier noted, the study assessed the implementation of parental participation in decision making in schools as per education policy guidelines. It is relevant to the education policy makers who underscored parents' roles in schools (URT, 2015; URT, 2016). As such this type of parental involvement theory is directly relevant to the study. It was the interest of the researcher to determine whether the policy aspects on parental participation in decision making in schools were implemented as stipulated in its guidelines and also test the theory as propounded by Epstein (1995). Parental partaking in decision making in schools motivates them to be involved in the implementation of resolutions passed by schools' stakeholders as they feel being part of their development. This is due to the fact that decision making involves bargaining and negotiation and resolving differences (Bell and Bush, 2002). It is influenced by personal and community values, attitudes, beliefs, needs, and goal clarity among others (Thungu, Wandera, Gachie, and Alumande, 2010). This leads to involvement in all other types as they emanate from decision making process. In decision making process, parents can be informed and made aware of the need for parenting, volunteering, learning at home, communication policies and for cooperating with communities.

All these activates can work effectively and efficiently depending on the way decisions are made in schools. In Tanzanian situation, they apply to school committees, improvement teams, parents- teachers' associations and others (URT, 2015; 2016). It is an effective means of participatory school leadership that has been found to be more effective and efficient (Okumbe, 1998; Bell \& Bush, 2002; Glanfield, Ngalawa, Simmt, 2015). The theory's strength was the cogent justification for its use on assessing parental involvement in this study

The sixth type of collaborating with community was applicable to the study. This type was also relevant as the policy guidelines emphasized on the need for communities/ parents to support schools through voluntary contributions, linking communities with schools through school governing boards and working with them for the development of the schools.

\subsubsection{Weaknesses of the Theory}

Much as it is for the first-time parents were given the opportunity to participate in decision making in schools, it was uncertain whether the theory's applicability was commensurate to the defined types. Learning at home did not directly apply to the study that sought to assess the implementation of the policy directives on parental involvement in decision making as per the provisions of the policy guidelines. The interests were more in school sites than at home. In this view, the theory's strength diminishes. 


\subsubsection{Justification for the Use of the Theory}

Despite the few weaknesses of the theory, it was to a larger extent applicable to this study. As the study focused mainly on parental involvement in decision making, the theory was considered fit to this study. Hence it was adapted to guide the study.

\subsection{Conceptual Framework}

The following diagram summarizes the concept.

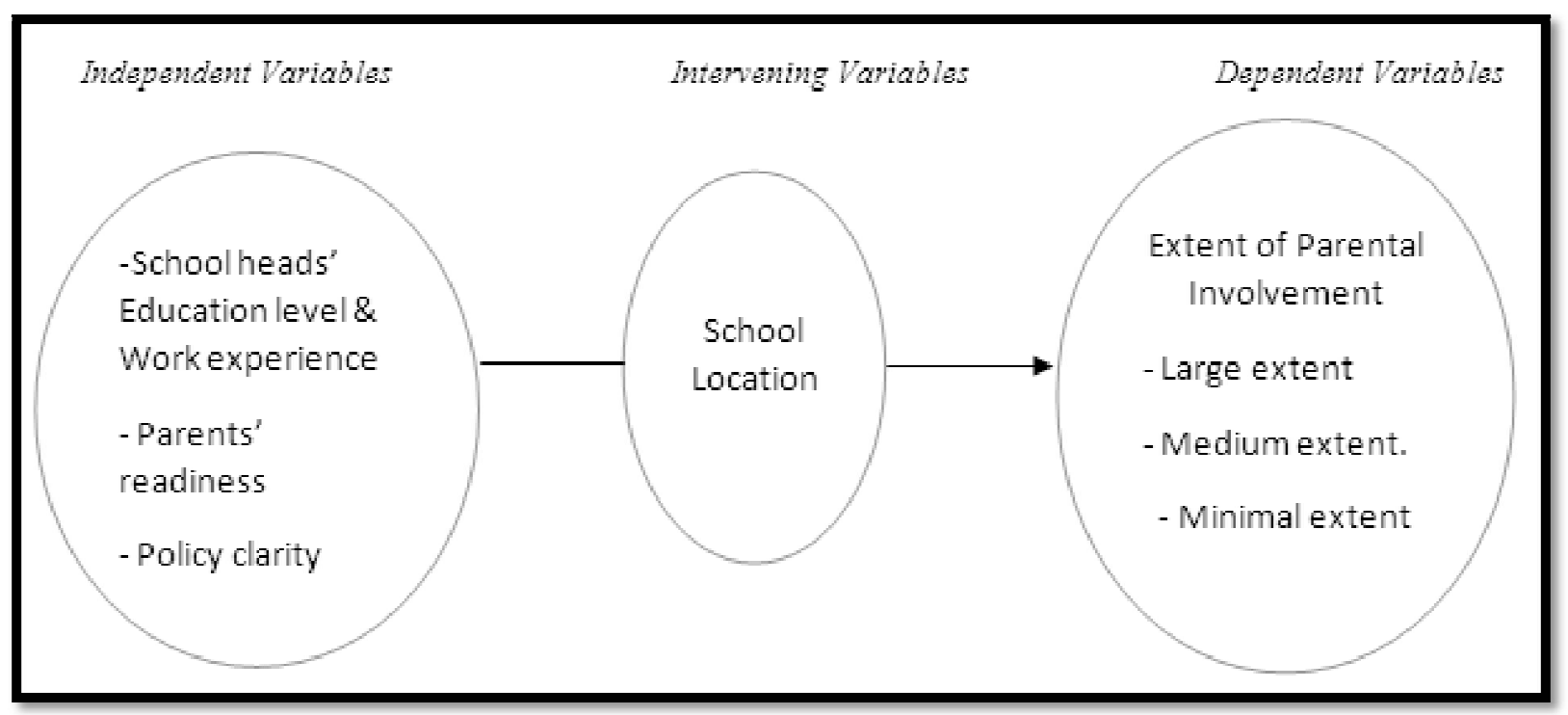

Figure 1: Conceptual Framework

Source: Adopted and Modified from Creswell (2014), Figure 3.1, P.89

As the diagram indicates, school heads education level and work experience could influence the degree they involved parents and their views on the extent of parental involvement. Parents' readiness to be involved and the policy clarity to both parents and teachers could determine the range of parental involvement. The same applies to geographical areas of schools. These were measured in questionnaires and hypotheses. These variables could subsequently affect the dependent variable (extent of parental involvement). These were considered important variables to be measured in this study.

\section{Literature Review}

Education directives in general are techniques of efficient and effective means of policy implementation in any country the world over. They direct on what and how schools should accomplish the tasks to achieve educational goals and objectives. This includes the guidelines on how stake holders such as parents can play their parts in the running of schools.

Recent studies indicate that it is not always that parents participate in decision making in schools. Sometimes they participate fully, at other times to a less extent and at extreme cases they do not participate at all (Rapp \& Duncan2012). Thus, not all education directives are completely implemented as intended. Sometimes they are executed as directed and sometimes not. For instance, though circular number 3 of 2016 directs heads of schools to launch parents/ teachers forum for discussing different matters pertaining to school development and submit their suggestions to the council executive director (URT, 2016, circular no 3, section v), it is not clear whether it is what is meant by involving parents in making resolutions in schools. Suggestions or proposals are not resolutions as provided by circular number 3 of 2016. Such a forum is not a decision-making entity and cannot come up with the resolutions.

The extent of parents' involvement in schools is determined by various factors. There are school related factors, policy related factors and parental related factors (Okeke, 2014; Sumarsono, Imron Wiyono and Arifin, 2016; Albez and Ada, 2017). These subsequently lead to variations in the extent parents involve themselves in schools in the USA and Canada, Europe, Asia and Africa. Some schools perform to high extent, others to a medium extent and some others to a low extent on parental involvement and result on respective school effectiveness.

Appropriate school administration and leadership have been seen to enhance parental involvement in schools. In their phenomenology study conducted in the city of Malang, Indonesia, Sumarsono et al. (2016) revealed that parental involvement was through parent - school committees that planned and evaluated education matters for improving quality education. They include school buildings, teacher training, students' affairs, public relations, educational financing and publications and organizing students' extra-curricular activities.

This entails full parental involvement and support to school that impacted on its improvement. In this view, parental involvement commensurate to the expected levels - the high extent. However, the study does not tell us whether such parental involvement was based on policy provision or was just out of other driving forces. It remains unclear whether such activities performed by parents were their own initiatives or were initiated by educators.

The researchers reported only of what was taking place as any other phenomenology study does. As such, it did not address parental implementation in the light of any education policy. The study had no legal backing but bases on 
mere practice. Even the level of elementary school may influence more parental involvement than secondary level as studies have indicated that parents are more involved on lower levels of their children's education than at the higher levels (Albez \& Ada, 2017; Zedan, 2012). Hence, it might be different at secondary school level.

When school leadership style matches with parental involvement, school improvement is affected and quality education delivery is enhanced. This is a result of the synergy of the school staff and parents' support. A qualitative case studyby Ngalawa, Simmt and Glanfield (2015) supports this contention. The parents supported Kitamburo Primary School in Kilolo District - Iringa, Tanzania, as they perceived it to be their institution and were involved in decision making on issues such as retaining and motivating teachers and general cooperation with the school administration. These resulted in school's improvement and in registering consistent high-level academic achievement at the primary school leaving examination of this rural primary school.

Nonetheless, this phenomenology study did not assess parental involvement based on some criteria. Above all, it did not seek to solve any education problem but just to get experience and share knowledge. All the more, it was a case study on a single primary school that may not necessarily apply to secondary schools and specifically to ward schools. There is no specification of parents' role in the study. It cannot be assumed, therefore, that all community members, who participated in the study were parents. It is also unclear whether parents had special attention in the study besides not linking that study to any education policy. It remained uncertain as to whether parents in community secondary schools in Rukwa region were involved in the same manner as per the education policy (circular 3 and procedure for voluntary contributions) guidelines and whether the schools were being improved.

While there are cases of appropriate parental involvement in schools, as the cases of Malang city elementary schools in Indonesia and Kitamburo Primary School in Tanzania, there are contrary findings in which parental involvement leaves a lot to be desired due to inappropriate school administration. Inappropriate school administration landscape is one of the factors behind inadequate parental involvement in schools. This view has research backing as disclosed by Albez and Ada (2017) in their quantitative study, whose findings showed that head teachers had inadequate arrangement for efforts to involve parents in schools in Turkey and that parents reacted accordingly. The participants (administrators, teachers and parents) indicated a need to put in place an elaborated strategy for involving parents in school as to enhance collaboration between schools and parents in order to improve education.

Whereas parental involvement in decision making is key to school effectiveness, some schools involve parents in other forms, not in decision making. For instance, Peiffer (2015) investigated the effect of self-efficacy on parental involvement in the secondary school level in Pittsburgh Public School District in Allegheny County, Pennsylvania, through a cross-sectional design using questionnaires (closed and open ended). Parents indicated that they did not participate in decision making as they had no forum for shared school governance. Though parents recognized the importance of conferences with teachers, they indicated concerns for lack of decision-making forum. Similar findings were reported by Mulwa, Kimosop, and Kasivu (2015) and Olayiwola and Alabi (2015)

However, it is not clear whether the heads of schools were guided by legal framework or not. There was no particular government directive to parents that was assessed in view of its implementation. Above all, only questionnaires were used to collect data. That parents desired to partake in decision making is not enough to be clear as to how effective they could have participated if the forum was offered. Even parents' concerns did not indicate that they had any legal backing

The descriptive survey report of Olayiwola and Alabi (2015) revealed that parents, as part of formal decision making, participated in making decisions about improving quality of teachers and physical facilities in schools in Nigeria. Other matters such as budgeting and students' affairs were not identified as areas of parental involvement in decision making. It is in this context that the researchers referred to it as micro - politics in decision making in schools. Decision making was relative to school heads. But the study is indifferent as to what legal frameworks provided for decision making in the schools. As only principals constituted the sample, the views of parents and other education stakeholders are missing in the report. It only tells on the extent of parental involvement in schools that is not guided by the policy but only normal practice. Furthermore, the study was not intended to solve any education problem but only to explore what was taking place in schools and to disseminate knowledge

Similar views were indicated by secondary school students in Kenya as recorded in a descriptive survey by Mulwa; Kimosop and Kasivu, (2015). Students viewed parental involvement as being the least in decision making in school management and that they were excluded in curriculum matters. As parents and education officers were excluded from the sample, the findings lack a wider perspective. No other views were explored apart from those of secondary school students. Additionally, it only covered policy and legal aspects. The way parents could be involved in curriculum implementation is unclear as they are not supposed to plan the teaching and learning in classrooms. Probably the educational officers could have clarified this issue if they had been included in the sample.

The issue of low parental involvement based on school factors have been reported also by several studies in Tanzania. There are several studies in Tanzania that have examined school related challenges as inhibitive of parental involvement in the institutions (Zahara, 2014; Kabir\& Aktel, 2014; Burilo, 2014).

Parental related factors equally count for the level of parents' involvement in schools in African countries. Ngigi's (2014) findings of a descriptive mixed methods survey confirmed that parental involvement in primary schools was little in Ndeiya, Kiambu County in Kenya. The researcher reported that primary education was adversely affected due to lack of parental interests in the schools in the area. The participants (teachers, parents and pupils) saw the need for parents to take part in running the schools. However, this study is also silent on policy and legal aspects. It does not appeal to regulations and guidelines of parental involvement. Even the other variables such as factors for such low level of parental involvement and efforts made to involve parents by school leaders are left out 
The legal framework of education in a country, determine the extent of parental involvement in education of their children. It can either favour parental participation in governing the schools or inhibit their desire to participate. It Tanzania, the legal framework is a challenge to parental involvement (Heystek, 2011; Makwinya and Komba, 2014; Kalolo, 2016). The legal structure of education is one of the determinant factors for parents' extent of involvement in schools. In most cases, parents are not adequately involved in decision making due to being non-members of decision-making bodies. This has been seen in different countries. The Tanzania government also admits this fact (URT, 1995, 2001; 2014)

The findings reported by Heystek (2011) on parents' low-level involvement in schools' governing bodies that the policy had hindered them from active participation in the management of schools in South Africa is a concrete example. Other factors for low level involvement of governing boards in schools included, parents' literacy and expectations, negative perceptions of principals and parents' readiness to attend the governing board meetings. This study focused on governing boards only as representative of parents. Whether parents were given special role in the policies remains unknown just as their perspectives. Only principals' perspectives were covered by this study.

Qualitative and quantitative studies confirm that the Tanzania legal frame of decision making hinder effective parental involvement. For instance, Kalolo (2016) reported that decision making in education in Tanzania is dominated by some interest groups in a form of governing boards, teachers' unions and policy makers while leaving aside parents and other stakeholders. The study revealed that decision making organs do not represent parents' and students' interests. This echoes the quantitative findings of Makwinya and Komba (2014).

Probably the new policy (2014) in the country would address this challenge as it amplifies the role of parents in running schools in basic education. Nonetheless, it depends on its implementation of which no one is sure of. Kalolo's study left out education officers in the sample (of 24 secondary school teachers, 24 parents and 52 students). Education officers' clarification could enrich the study much as it focuses on policy issues. The study missed their views, thus neglecting their important role in policy formulation, implementation and evaluation.

Official involvement of parents in decision making in organs in schools is a factor for either their active participation or not. Makwinya and Komba (2014) studied on Community - School Partnership in Morogoro urban -Tanzania by exploring the role of parents' perceptions on communication and democracy in the partnership. Quantitative approach was used in a survey design. The sample comprised 10 wards from which 250 parents were selected. Structured interview guide and questionnaires were used to collect data. The study revealed that parents were not satisfied by the communication frequency and that some school matters were never communicated to them. They also indicated that they were not comfortable with the composition of school governing boards.

The study was about parents' views on community - school communication and whether there was democracy in making decisions. It had nothing to do with specific roles and powers of parents based on education policy. The study was quantitative and, therefore, could not access in-depth information regarding parents' viewpoints besides not involving school heads, who are important stakeholders in educational practices. It was delimited to school boards composition and ignored parents' meetings and other fora for decision making in schools

Similar views were reported by Kapela (2012) after investigating on the roles of school boards in managing school funds using a case study design in Mbozi District in Tanzania. Findings indicated, among other things, that the format for selecting board members made heads of schools to select the individuals who were not effective so as to manipulate them. Mbazi (2015) has also recommended the review of the procedures of electing board members, though not targeting parents. This implies that there is need to review school board format. The researcher was not interested with sharing decisions in schools with parents.

When parents and other stakeholders are left out during policy formulation, their involvement in implementation stage becomes challenging as they do not own the plan. Thus, sometimes literature remains indifferent on whether parents were involved in decisions made or not but they appear in the implementation stage in selected aspects. For instance, Tesha (2012) reported that salaries of non-teaching staff were paid through parents' contributions after analyzing the roles of school leadership in promoting academic and social development of the school in Meru community (Tanzania) in government secondary schools. However, the study did not clarify whether parents were involved in making of decisions to pay those non-teaching staff or not. What is clear is that parents implemented what was decided in schools but how the decisions were made is not known. It is also unknown whether the contributions by parents were based on policy or not. Whether the contributions were initiated by parents was also unknown

Common practice on parental involvement can make parents participate in some school running aspects. It becomes a tradition without specific education policy. Though no concerns might not be exhibited by either school administrators or parents and other stakeholders, full parental inputs into schools remains questionable. It is as if it were a laissez faire kind of school leadership creating the impression of ineffective school management. In this view, communities might support schools financially because of the culture that has been established by the system and history. This does not necessarily mean that they also participate in school decision making. For instance, Kakulu (2014) investigated causes, magnitude and education measures of teachers' attrition in community secondary schools in Sumbawanga District (in Rukwa region), Tanzania. Findings indicated, among others, that school management got support from parents and community members in order to retain teachers in the district through contributions for extra duty allowances. This was based on the agreements made between school management and parents

The study reported on the agreement of school management and parents on financial contributions but did not explain how the agreement was made, i.e. the forum was not known. It was unclear whether it was initiated by parents or imposed by the school management. It was also unclear why not all parents cooperated since teachers reported that some parents did not contribute. 
The reviewed studies indicate that parental involvement was generally to a low extent in the respective countries (Zahara, 2014; Okeke, 2012; Olayiwola and Alabi. 2015; Ngigi, 2014). Only a few studies such as Sumarsono et al. (2016) in Indonesia and Ngalawa et al. (2015) in Kitamburo - Iringa, Tanzania reported a larger extent of parental involvement in schools. In both cases, factors responsible for the extent of parental involvement include school leadership style, parents' factors and education legal framework. None of the studies addressed parental involvement as guided by the education policy. Evidence is lacking on whether the Education policy guidelines introduced have made a difference in Tanzania, hence the need for its assessment.

Literature indicates that Rukwa region faces a number of educational challenges that pertain to parents and the local community. They include the local community not valuing education, lack of formal education to most parents, lack of educational awareness, and lack of cooperation of parents with educators, among others (Ndasi, 2003; Mhegera, 2011; Nyandwi, 2014; Mshani, 2015; Siyame, 2016; Yassin, 2017) and lack of resources in schools among others (URT, 2014). These made the level of parental in schools' involvement questionable. Some parents purposely planned for their children to drop from schools (Mhegera, 2011; Siyame, 2016 b) and even harassed and assaulted teachers (Yassin, 2017; Mshani, 2015).

The reviewed literature showed lack of information on the level of compliance with the policy guidelines with regards to parental involvement in ward schools in Rukwa region. The questionas to what could be the extent of ward school's compliance with the policy guidelines, that intended to scale up parental involvement in decision making in schools, was not answered. Whether the policy guidelines motivated parents to get more involved remained covered. The same applied to whether the analyzed challenges on parental involvement in the region were no longer setbacks.

\section{Methodology}

The study employed mixed research design that concurrently collected both qualitative and quantitative data. The qualitative data was used to extend and to compare the quantitative data for significant answering the research questions and for better understanding of the research problem.

The target population included District Educational Officers (DEOs), Ward Education Officers (WEOs) Heads of Secondary Schools (HoSSs), chairpersons of school governing boards (CSGBs) in community secondary schools, teachers in management teams (TMTs) in schools and parents having children in the schools and were responsible for their education, who were found in Rukwa region and all Ward Schools in Rukwa region were targeted in this study. The researchers opted to select 40 heads out of 70 school heads in the region and 40 of the 280teachers in the school's management teams. Then one WEO and one CSGB in each school plus one DEO from each of the four districts.

Both probability and non-probability sampling procedures were used to select participants of the study. The study utilized questionnaires and interview guide for data collection. Pilot testing was conducted in four schools that werenot included in the sample. Pilot testing the questionnaires was made to 4 HoSSs, 4 CSGBs, 4 WEOs, 16 TMTs and to 30 parents to enable the researcher to check for language clarity, relevance to research questions, understandability, and spacing for responses. Pilot testing the interview guide was done to 4 HoSSs. It tested practicality, time needed for interview, communication ability of participants and relevance of responses to the research questions. The researchers made relevant corrections of the weaknesses identified during pilot testing of both instruments and made needed changes on the instruments for improving their validity.

\section{Findings and Discussions}

The policy guidelines provided that parents should be involved in all decisions and resolutions made for major plans in the schools and that the school boards were to link parents with their institutions. They further specified that parents should be involved in decisions on matters of provision of food, hiring of part-time teachers and security personnel and initiate voluntary contributions for such costs (URT, 2016).

The research question sought to examine the extent to which the management of ward schools in Rukwa region complied with the policy guidelines on parental involvement in schools. The underlying logic of this research question was that, in order to achieve the government's objectives of widening the scope of parents' involvement in the management of schools and subsequently enhancing the legitimacy of decisions made and ensuring accountability therein, depended on the extent the management of the institutions was in keeping with the education policy guidelines.

The aspects of compliance with the policy guidelines that were explored included parents' participation in decision making in line with the education policy guidelines, adequacy of parents' involvement in the school governing boards, the extent of the implementation of the policy guidelines in the schools and the testing of null hypotheses. The data were collected from DSEOs, WEOs, heads of schools, CSGBs, teachers in school management teams and the parents. The results are presented, interpreted and discussed based on the identified aspects of compliance with the guidelines. Some of the quantitative findings are summarized in Tables 1 to 4 and then followed by the presentation of the qualitative findings and finally the discussion of the findings.

\subsection{Parents' Participation in Decision-making in the Schools}

The first aspect measured whether parents were involved in decision making in the ward schools in Rukwa region. This could determine the implementation of the guidelines that required parents to be involved in the decision making on major plans in the schools. The information on this aspect was obtained from CSGBs, WEOs, DSEOs and parents.

The findings from the questionnaire (yes/ no) responses of the CSGBs revealed that 18 (90\%) participants agreed that parents participated in the decision-making processes in their schools. $2(10 \%)$ participants did not respond to the 
item. Some CSGBs identified the areas that involved parents' participation including students' discipline, provision of school equipment and furniture, food for students, voluntary contributions for school needs and extra learning classes. One of the CSGB who responded to the questionnaire indicated that some of the decisions made that involved parents were on constructing classrooms and toilets plus providing their own labour power contributions.

This means that parents participated in the decision-making processes in the schools. Findings further showed that the CSGBs were convinced that parents had a stake in decision making in the ward schools. The high agreement of the CSGBs that parents took a stake in decision making in the schools could have been influenced by their office in the schools as they were responsible for representing parents in the meetings. Some ward education officers confirmed that parents were actually participating in the decisions made in the visited schools

Out of 181 parents who responded to the item, 156 (86.2\%) parents confirmed, in yes/no responses, that they were involved in decision making while 25 (13.8\%) indicated that they did not take part in decision making in their schools. Majority of the parents indicated, therefore, that they took part indecision making in the schools. The parents' responses concurred with those of the chairpersons of school governing boards to a large extent

The third aspect determined whether parents were involved in decision making in ward schools in line with the policy guidelines. The responses were obtained from the DSEOs, WEOs, HoSSs and teachers. Findings from questionnaire (yes/ no responses) administered to the WEOs and teachers in management teams in the schools revealed that twenty-four (92\%) WEOs and 22 (64.7\%) TMTs confirmed that parents participated in the decision making in schools in line with the policy guidelines. A few WEOs (7.7\%) and more than a third (35.3\%) of the teachers indicated that parents did not take part in decisions made in the schools according to the guidelines. Some WEOs stated further that parents were part and parcel of the decisions made in the schools. These results are slightly different from those of the CSGBs. This was probably because the CSGBs represented parents in the decision making in the schools and so they reported that they took part in the decisions in line with the policy guidelines. However, it is worth noting that the parents' participation in decision making varied from school to school.

Some ward education officers, who indicated that the parents were involved in decision making in schools, explained that the schools had parents' meetings, school committees and that in some schools the management met with parents four times a year. Some WEOs reported that parents were involved in making decisions on matters of students' discipline, food, school buildings such as classrooms, toilets, teachers' houses, furniture, academic matters and school finances. Parents' responses echoed the same areas of their involvement. WEOs reported further that parents were represented also in the school governing boards. Other WEOs explained that some parents made follow-up of their children's academic development and planned with teachers on improving performance in the schools. One WEO said that before the provisions of circular number 3 of 2016, parents did not participate in decision making in schools; however, after the release of the circular, parents were able to participate. Some WEOs stated that parents' meetings formed the main forum for their participation in decision making in the schools.

However, 2 (7.7\%) WEOs indicated that parents did not take part in decision making in the schools. They explained that they did not turn up to the meetings and that, sometimes, the quorum for the meeting with them made it not practical to involve them in decision making and that parents believed the government could do everything. One WEO's response read, "They think that they are not responsible because the government can do for them each and everything. They even think that decisions on their schools can be made by the government". The challenge of long distance from some schools was another factor for parents' failure to take part in making decisions in the schools.

Some of those teachers who responded positively (yes) explained that parents were involved in decision making in schools through parents' - teachers' meetings or their representatives in the school governing board meetings. During such meetings, proposals on various issues related to the schools such as dormitories for accommodation of students, food services, physical infrastructure, and students' guidance counselling services and plans on how to improve students' academic performance were discussed. They added that the parents by then had a positive attitude towards their schools. Response from one of the teachers read; "The parents participate in school decision making at our school. For instance, during last meeting parents decided to contribute money for their children's food". The teacher elaborated that the issue was raised by some parents during the Parents' Day meeting at their school. Another teacher's response was: "Many parents are getting involved and do make good decisions. For example, parents introduced and do manage the hostel contributions because nowadays many parents have positive attitude and as a result student get porridge at our school".

However, other teachers remarked that some parents did not attend parents' meetings and this hampered their effective involvement. Some of those teachers who reported that parents did not take part in decisions according to the policy guidelines on parental involvement argued that, since the government had made education free, it had affected parents' involvement in the schools. Other teachers reported that parents' low level of education or lack of awareness on the significance of education inhibited their involvement in decision making in the schools. One teacher remarked: "Most parents in Rukwa region and particularly in our ward are not aware and do not care about education. There is poor attendance in parents-teachers' meetings for discussing academic matters". Another teacher expressed a similar observation when he wrote: "According to my experience, parents are not participating in our school's decision-making meetings because of their low level of understanding (low knowledge) and because of the nature of the directives given by the government authorities".

Another teacher also reported that most of them were not turning up during parents - school meetings because they did not know the importance of their presence in the schools. Some teachers reported that some contradicting orders and misinterpretations of the policy by some of the government officials made parents decline to take part in decision making in the schools. This went hand in hand with the top-down approach of the government that created misunderstanding of the guidelines among parents and thus hampered the parents in involving themselves in the schools' 
activities and plans. Some teachers reported that political issues also affected parents' participation in decision making in their schools. They provided details that showed how the political ward leaders were opposing the directive for the parents to work with school management for their personal issues which hindered school development plans.

The DSEOs and the HoSSs were interviewed on this aspect. During the interview with the heads of schools, the heads identified the areas in decision making that parents were involved. They included academic issues such as planning for extension of teaching and learning hours, provision of food to students, hostel issues, discipline matters such as truancy and pregnancies, planning for physical facilities of buildings and equipment, budget issues, school environment upkeep and security among others. The teachers in management teams echoed the same aspects that involved parents for decisions in the schools. The various areas in which parents were involved in were relevant and in line with the provisions of the education policy guidelines.

Some school heads maintained that some parents were taking part in decisions but not as expected. Other heads of schools said that the parents were actively involved in taking part in decision making whereas some pointed out that parents no longer had interest because of the government's inappropriate approaches to parental involvement in the schools.

Three DSEOs were concerned about the effect of parents' freedom to take part in school decisions and implementations. One DSEO remarked; "Since some parents take part in decision making while others not, the result is the emergence of classes amongst the parents and students in education". (Source: interview on 06/02/2018). The officer added that this had affected the implementation of the guidelines as it was being executed at varied levels in the same district. The officer further clarified that the division among parents and students was contrary to the aim of fees free basic education that sought to provide the service equally to all Tanzanian students.

Parental involvement in decisions in accordance with the policy guidelines seemed divided on the implementation of the guidelines. The divisions of students and parents were contrary to the 2014 education policy that aimed to provide quality education to all Tanzanians. This is even opposed to the national agenda of industrialization in relation to the role of education that require all students to have equal access to quality education. Hence, students should not be classified based on the socio-economic status of their parents (Mufuruki; Marwa; Kasiga, and Mawji, 2017).

Legitimate and accountable decisions in schools depend on the stake given to different stakeholders such as parents for our case. While it is so important for ensuring accountability and legitimacy in the implementation of the decisions, not all schools had parents' inputs in the making of major decisions in the schools. Therefore, some schools made legitimate and accountable decisions based on parental involvement and this was in keeping in line with the policy guidelines.

However, the scenario implies that not all decisions had full legitimacy in some of the schools as not all parents took part in all major decisions made in the institutions. This minimized the levels of accountability in the schools. It even hampered the government's move on its attempt to legitimize the decisions made and enhance accountability in the school's vis-a-vis parental involvement in the schools. The government and other stakeholders should team up to ensure that parents have a stake in making decisions for ensuring the legitimacy and accountability of the same in the light of the fees free basic education policy.

Adequacy of Parents' Involvement in School Board Meetings. One of the aspects of parents' participation in decision making is having a stake in the school governing board meetings, which are the official organs for making decisions. The 2014 Education Policy guidelines insist that the schools' governing boards link parents with the institutions (URT, 2016). The researcher was interested to find out whether the boards involved parents in decision making as per the guidelines. The information on parents' involvement in the school boards' meetings was obtained from WEOs' questionnaire responses.

The findings revealed that more than three quarters (84.62\%) of the WEOs indicated that parents were adequately involved (represented) in the school governing board meetings and less than a quarter (11.54\%) indicated they were not adequately represented. Some of those participants who indicated that parents were adequately involved in the governing board meetings in the schools gave the reasons that school board members and committees were representatives of parents and that some parents were invited to attend the board meetings.

Those who indicated parents were not adequately involved in the governing board meetings explained that there were no parents' meetings prior to board meetings and that the board meetings were fixed on special calendar days that could not consider parents' issues. Hence, the boards did not give space for parents' views. Confirming this, one of the WEO explained, "Largely, parents don't know when the board meets unless for specific matters that can rarely occur".

This implies that the legal framework for decision making was still a challenge on parental involvement in some schools in the region. Much as the governing boards were the main organs for decision making in the schools and that not all parents attended such meetings in some schools, their involvement and representation could be possible only in those schools where they actively took part in the school parents meetings and in schools that had such meetings prior to the governing board meetings. Since the government insisted that the governing boards shall remain the link between schools and parents, and that parents must be involved in all major decisions in schools (URT, 2016), then the legal framework for the same needed to be developed and aligned with the policy.

For all the major decisions to be legitimate in the schools, parents must have a stake in them for accountability reasons. The schools that involved parents, even in governing board meetings, could achieve the government's set objectives. The contrary is also true that for those schools that did not involve parents' views and ideas, this might not be realized. There is need to balance the composition of board membership and modality of the board meetings. All schools should ensure that they meet with parents prior to the governing board meetings in order to fulfil the government requirement of involving parents in all major decisions pertaining to the development of the schools. Training for CSGB 
members and heads of schools ought to be done to upgrade the parents' potential for effective involvement and to ensure making of sound decisions.

\subsection{Extent of Implementation of Policy Guidelines on Parental Involvement}

The researcher also sought to determine the extent of the implementation of the policy guidelines on parental involvement in decision making in the schools. The extent of policy implementation meant the extent of achievement of the government objectives on this aspect of parents' involvement in the schools. The results were obtained from rating responses of heads of schools and WEOs based on questionnaires' responses and from the interview with the HoSSs and the DSEOs. Table 1 contains a summary of results from WEOs and school heads' rating responses.

\begin{tabular}{|c|c|c|c|}
\hline \multicolumn{2}{|c|}{ HoSSs' Responses } & Frequency & Percentage \\
\hline \multirow{4}{*}{} & minimal extent & 11 & 39.28 \\
\cline { 2 - 4 } & medium extent & 11 & 39.28 \\
\cline { 2 - 4 } & Not sure & 6 & 21.43 \\
\cline { 2 - 4 } & large extent & 28 & 100.0 \\
\cline { 2 - 4 } & Total & Frequency & Percentage \\
\hline \multirow{4}{*}{ WEOs' Responses } & 9 & 34.6 \\
\cline { 2 - 4 } & minimal extent & 13 & 50.0 \\
\cline { 2 - 4 } & medium extent & 3 & 3.8 \\
\cline { 2 - 4 } & Not sure & 26 & 11.5 \\
\cline { 2 - 4 } & large extent & 300.0 \\
\hline
\end{tabular}

Table 1: Weos and Hosss' Extent Rating of the Policy Implementation

Data in Table 1 show that 11 (39.28\%) school heads and 9 (34.6\%) WEOs indicated that the policy guidelines were implemented to a minimal extent. Eleven (39.28\%) school heads and 13 (50\%) WEOs indicated that they implemented the guidelines to a medium extent. Six (21.43\%) school heads and $3(11.5 \%)$ WEOs indicated that the policy guidelines were implemented to a large extent. One (3.8\%) WEO was not sure. During interview with the DSEOs, three officers (DSEOs) ranked the implementation to a medium extent and one DSEO ranked it to a large extent. This implies that the government's objective of enhancing parental involvement in planning for major school development activities was implemented at varied extents in different ward schools in Rukwa region. Generally, the policy was implemented to a medium extent.

Some school heads claimed that the minimal implementation of the policy guidelines was as a result of parents' low level of involvement. They further argued that it was due to parents' lack of clear understanding of the education policy guidelines, their attitudes toward involvement in schools and political influences. They added that the minimal extent resulted from parents' tendency of not valuing education. This was confirmed by one of the heads of schools who stated; "Very few parents attend meetings and they have negative attitude toward being involved in the school. Education for their children is not their priority".

The heads of schools elaborated further, through the questionnaire, that parents had failed to specify the role they were supposed to play in the management of the schools due to being confused by the politicians. This made parents not to be directly involved in various school activities and, therefore, the policy guidelines were implemented to a minimal extent. Corresponding with this revelation, one school head stated; "The parents have not understood the education policy well and therefore they have deserted the matters related to education at school; hence, their involvement in the implementation of the policy guidelines is to a minimal extent".

Another head of ward school said that the policy was not clear to majority of the parents while another one pointed out that the implementation of the policy was a one-way traffic and that the government was doing it in its own way. As a result, the policy implementation was at minimal level.

The heads of schools identified the areas in circular number 3 of 2016 that needed more clarifications. They included guidelines on the costs of matters such as sports and games, mock examinations and medical services. They suggested that these aspects should be clearly stated in the policy guidelines as parents thought that the items were not concerning them and so they were reluctant to partake in planning for such activities in the schools. They thought that it was still cost-sharing in practice much as education costs were not only school fees.

Some of those heads of ward schools, who rated the implementation of the policy guidelines at the medium extent, said that somehow parents were involved in different school decision making and management activities. Some gave details by explaining that parents had little awareness of the education policy guidelines that concerned them and so not all of them participated in decision making in schools in line with the policy. The other heads of ward schools reported that parents appeared only when asked to go to school and some of them never responded to the school invitations. Some other heads of schools attributed the medium parental involvement to misinterpretation of the policy by some politicians. One head of school stated:

The government leaders and some politicians are misinterpreting the policy to the parents. The parents have been made to believe that the burden of running the schools is left to the government. Even those parents who had been active in school involvement have now declined. 
Conversely, few school heads rated the implementation of the policy guidelines that concerned parents, at a large extent level. They explained that parents were involved in different school activities through representation in committees and parents' meetings. They added that parents considered ward schools to be their own institutions and so were cooperative to school management. The HoSSs confirmed that they involved parents and managed schools in line with the policy guidelines.

During the interview, some school heads reported that parents were generally ready to take part in some decision making in schools and in their implementation. One school head said; "Parents are nowadays more cooperative and get involved more in our school than the period before this education policy was launched" (Source: interview on 31/ 01/ 2018). The other head of school said; "The parents are participating at the rate of about 95\% in decision making at our school. Everything which is done for their children must be discussed with the parents" (Source: interview on $15 / 02 / 2018$ ). The head of school gave the details by saying that parents took part in deciding on matters of academics, budget, students' discipline and plans on school buildings and hostel. The head attributed the improved learners' academic achievement in the school to the active parental involvement in the school.

However, all of the heads of schools said that they had never received any proposal on voluntary contributions to the schools from parents. They said that the main obstacle to parents' involvement was the government's approach that was confusing and discouraging them. They clarified that some parents were aware of their roles in schools but had never proposed any voluntary contributions. One head of school said:

Parents expect the school management to initiate the idea of voluntary contributions in our school. They believe the school management knows the needs in the school and so they rely on the management. Even the implementation of the decisions that we involved parents is a challenge at our school. (Source: interview on 16/ 02/ 2018).

These responses imply that the directive that parents should, in a wide community, initiate voluntary contributions in the schools had not been implemented in all the schools by the time the data were collected in the region. This item of the guidelines was the most challenging one to policy implementation.

Some school heads were also concerned about the government's approach to the policy implementation by claiming that it did not consider different school environments and that it confused and discouraged parents from active participation in decision making, especially on those issues involving financial and material contributions. Some other participants responded by stating that the policy was generally good but the modality of its implementation by the government was inappropriate. They elaborated further by claiming that this approach affected resource acquisition for the teaching and learning and subsequently learners' academic achievement.

The three DSEOs rated the implementation to a medium extent and attributed this performance to the attitudes of parents and political influences. One DSEO remarked; "Some parents do not value education and have negative attitudes towards being involved in decision making and implementing the decisions on education in the schools" (Source: interview on 06/ 02/ 2018). The officer said that this had categorized students into two classes of the well served and the poorly served based on parents' level of involvement.

One DSEO remarked that the policy was implemented at a large extent because the parents were actively taking part in decision making and in its implementation process. The DSEO clarified that parents were cooperative and responded positively to matters of education. The participant added that the parents contributed money for hiring parttime teachers, constructing school buildings and in maintaining students' discipline as well as provision of other education needs to their children. The DSEO stated that parents' involvement had reduced truancy and school dropout rate in the region.

The results echo that of the Rapp and Duncan (2012) study on the extent of parents' involvement in schools, which revealed that some did get involved while others did not. Implementation of education plans and policies depend on stakeholders' participation (Kisembe and Were, 2014). Their involvement enhances interaction with teachers and other parents and ensures meaningful education in the schools (Mahmoud, 2018) and uplifts school effectiveness (Glanfiel, Ngalawa \& Simmt, 2015). Parents must have their roles to play as they have an interest in their children's education and have enrolled them in schools. When they neglect their roles, therefore, they diminish education effectiveness and efficiency in schools. The findings are in agreement, to some extent, with the first and third levels of the three levels construct model that was developed by Hoover-Dempsey and Sandler (1997) as described in Chapter One and elaborated in Chapter Two. Parents' involvement was thus partly influenced by their role perception in their children's education as well as the school leadership style.

These results imply that the extent of policy implementation differed in the region depending on different factors. The minimal and medium extents of implementation had significant policy implications. Parents' interests, priorities and opinion were not adequately captured in the policy implementation. It means the government's objective of enhancing the legitimization of decisions on matters such as finances, students' management, academic issues and other plans lacked parents' inputs. Their role performance of monitoring and reporting malpractices in implementing the fees free education policy diminishes. There must be further strategies to improve parental involvement to implement the policy to a large extent. The region shall lag behind in education until when this challenge is decisively addressed.

The minimal and medium extent of implementation applies also to the minimal and medium legitimization of major decisions on school development. It stands to reason that there are illegitimate decisions in the schools to some extent. These make the management in the school's work under legal challenges that weaken school effectiveness and accountability. These findings are aligned less to theories of parental involvement such as the Epstein (1995) fifth and sixth type of involvement and participatory decision making in education that have been proven effective in education planning and leadership. The principle of education practice of working with parents for enhanced education management was also slightly applied in the area of study. There is need to make relevant intervention to see to it that parents take part 
in making of decisions and resolutions in schools for the policy to match the implementation with desired goals and objectives.

\subsection{Parents' Involvement in Implementing the Decisions}

Aspect number six sought to determine whether parents were involved in the implementation of the decisions made in the schools. Data were obtained using the questionnaire responses of CSGBs' and interview with heads of schools.

Findings from questionnaire scores of CSGBs on parental involvement in implementing decisions revealed that 17 (85\%) participants agreed that parents participated in the implementation of the decisions made in the schools and 2 (10\%) participants disagreed with the item. 1 (5\%) did not respond to the item. This means that majority of the participants witnessed parents participate in the implementation of the decisions.

The chairpersons who responded positively explained that parents were involved in various decisions in schools through parents-teachers' meetings in schools and ward meetings that discussed education matters. They explained in details that parents actively took part in implementing the decisions on matters such as food and hostel services, plans on improving academic performance, physical facilities and students' discipline.

The chairpersons who responded negatively explained that parents did not participate in decision making and in the implementation of the decisions as they did not turn up in meetings or even respond to their invitations to the schools. They explained that it was due to parents' ignorance on policy guidelines, illiteracy, and lack of awareness on matters of education and that they were not properly prepared to partake in the policy implementation. One chairperson answered; "Most parents do not know the policy guidelines and therefore education for these parents is needed on this matter". Another chairperson wrote; "Many parents do not know the guidelines for they were not prepared earlier on this exercise. They cannot report the malpractices as they did not know them".

Most chairpersons agreed that parents had a stake in the implementation of the decisions made in schools as compared to what was indicated by heads of the institutions. This could be the result of the CSGBs taking part in decisions on behalf of parents while, probably, the school heads based their argument on involvement of each individual parent. The level of parents' involvement could also count for this variation as the item did not include the level or extent of involvement.

During the interview with the heads of schools, some participants said that parents were actively taking part in the implementation of the policy guidelines. One head of school said; "Parents of students in our school participate in implementing the resolutions without problems. The only challenge we have is political influence that mislead them" (Source: interview on 31/01/2018). Contrary to this remark, some other heads of schools said that parents were reluctant to take part in the school decisions even when they took part in their making. One head of school said; "Parents do agree with the resolutions in our meetings but when it comes to the implementation stage, they decline. So, the implementation of the resolutions is a challenge at our school" (Source: interview on 30/ 01/ 2018).

Nonetheless, all categories of participants indicated that some parents were involved while others said were not. The differences could be at the involvement levels. Planning and implementing education matters is important for effective service delivery in education. When all stakeholders play their part, implementation of education policies and plans become successful when translated to action. In order for the policy to bear the desired results, parents must actively participate in the implementation of the resolutions. When parents cooperate with schools, school's effectiveness in handling its issues is realized (Glanfiel, Ngalawa and Simmt, 2015). The contrary applies to when parents don't play their part in the implementation of education policy, general performance in education declines (Lawuo, Machumu and Kimaro, 2015). The government and all other stake holders should see to it that parents get involved in school adequately. This should go hand in hand with decisively addressing the respective hindrances.

\subsection{Testing Hypotheses}

The researcher was interested to understand the nature of the characteristics of some of the data in relation to variations in school heads' responses on the extent of the implementation of the policy guidelines on parental involvement in the schools. For all the null hypotheses tested in this study, the decision rule is that if the p- value is equal to or less than the significance (alpha) level of .05, the null hypothesis is rejected. If it (p) is greater than the alpha level of .05, we fail to reject the null hypothesis. The SPSS was used in computing all statistical tests.

\subsubsection{Hypothesis Testing 1}

One-way Analysis of Variance (ANOVA) was done to determine whether school location had significant influence on the mean rating scores of the heads of schools on the extent the policy guidelines were implemented in their schools. This model (ANOVA) compares the mean scores of two or more than two groups (Field, 2013; Brase and Brase, 1999). The model was used in this hypothesis test as there were three groups of heads of schools, namely those from the urban, the rural coastal and the rural uplands zones. The null hypothesis states as "There is no significant difference in the mean rating scores of school heads on the extent of the implementation of the policy guidelines on parental involvement in decision making in ward schools in Rukwa region based on school location". A four-point rating scale of not sure $=1$, minimal extent $=2$, medium extent $=3$, and large extent $=4$; was used to generate the data.

\subsubsection{Assumptions of ANOVA Include}

Approximate normal distribution of dependent variable, homogeneity / similarity/equality of variances of dependent variable groups, the samples have been randomly selected from the population and that dependent variable is 
either interval or ratio. The assumptions of normality and homogeneity were checked / tested. The SPSS test results are summarized in Table 2.

\begin{tabular}{|c|c|c|c|c|c|c|c|c|c|}
\hline \multicolumn{10}{|c|}{ Descriptive } \\
\hline & \multirow[t]{2}{*}{$\mathrm{N}$} & \multirow[t]{2}{*}{ Mean } & \multirow{2}{*}{\multicolumn{2}{|c|}{$\begin{array}{c}\text { Std. } \\
\text { Deviation }\end{array}$}} & \multirow[t]{2}{*}{$\begin{array}{l}\text { Std. } \\
\text { Error }\end{array}$} & \multicolumn{2}{|c|}{$\begin{array}{l}\text { 95\% Confidence Interval } \\
\text { for Mean }\end{array}$} & \multirow[t]{2}{*}{ Minimum } & \multirow[t]{2}{*}{ Maximum } \\
\hline & & & & & & $\begin{array}{l}\text { Lower } \\
\text { Bound }\end{array}$ & $\begin{array}{l}\text { Upper } \\
\text { Bound }\end{array}$ & & \\
\hline municipality & 8 & 1.6250 & \multicolumn{2}{|c|}{1.06066} & .37500 & .7383 & 2.5117 & 1.00 & 4.00 \\
\hline rural coastal & 5 & 2.2000 & \multicolumn{2}{|c|}{1.09545} & .48990 & .8398 & 3.5602 & 1.00 & 4.00 \\
\hline rural upland & 15 & 2.2000 & \multicolumn{2}{|c|}{1.20712} & .31168 & 1.5315 & 2.8685 & 1.00 & 4.00 \\
\hline Total & 28 & 2.0357 & \multicolumn{2}{|c|}{1.13797} & .21506 & 1.5945 & 2.4770 & 1.00 & 4.00 \\
\hline \multicolumn{10}{|c|}{ ANOVA } \\
\hline & & \multirow{2}{*}{\multicolumn{2}{|c|}{$\begin{array}{c}\text { Sum of Squares } \\
1889\end{array}$}} & \multicolumn{2}{|c|}{$\mathrm{df}$} & \multicolumn{2}{|c|}{ Mean Square } & $\mathrm{F}$ & Sig. \\
\hline \multicolumn{2}{|c|}{ Between Groups } & & & \multicolumn{2}{|c|}{2} & \multicolumn{2}{|c|}{.945} & .714 & .499 \\
\hline \multirow{2}{*}{\multicolumn{2}{|c|}{$\frac{\text { Within Groups }}{\text { Total }}$}} & \multicolumn{2}{|c|}{$\begin{array}{c}1.889 \\
33.075\end{array}$} & \multirow{2}{*}{\multicolumn{2}{|c|}{$\frac{25}{27}$}} & \multirow{2}{*}{\multicolumn{2}{|c|}{1.323}} & & \\
\hline & & \multicolumn{2}{|c|}{34.964} & & & & & & \\
\hline
\end{tabular}

Table 2: Results of Hypothesis Test (One Way ANOVA)

The descriptive test results in Table 2indicate the mean scores of heads of schools from municipal zone $(\mathrm{M}=1.63)$ are different from those of the rural coastal and rural upland heads of schools (both $M=2.2$ ). However, the ANOVA test results indicated that there was no significant difference in the mean rating scores of participants, $F(2,25)=.714 ; p=$ .499. The findings indicated that $p$ value of .499 was greater than .05 value of significance level. Based on these results, the researcher failed to reject the null hypothesis and concluded that there was no significant difference in theme and rating scores of school heads on the extent of implementation of the policy guidelines on parental involvement in ward schools in Rukwa region based on school location. The logical differences were out of random chance.

The tests results mean that the extent of the policy implementation on parental involvement in the region did not vary by reason of school location. The results imply that the factors affecting parental involvement in the schools were not significantly different in the school location areas.

Factors identified earlier such as low value attached to education, parents' awareness and readiness to take part in their roles in policy implementation in the schools and political forces were at the same levels in the municipal areas, rural coastal and rural upland areas.

The parents in municipal areas were supposed to be more actively involved in the schools (Prater; Bermudez; and Owens, 1997, Pansiri and Bulawa, 2013; Mapako; Mareva and Chindedza, 2013) due to their higher level of awareness and understanding due to the influence of location where there is high level of knowledge sharing and educated masses. However, the findings prove the contrary since the challenge of low-level parental involvement was the same regardless the different locations of the schools. It is a significant challenge that needs concerted efforts of stakeholders to address it. This is a unique result that is opposed to other studies. Probably political and cultural influences were the factors affecting parental involvement as previously reported.

\subsection{Hypothesis Testing 2}

The researcher made further test of Two-Way ANOVA on education level and work experience of school heads to determine whether there was any interaction and main effect of education level and work experience on the mean rating scores of the extent the policy guidelines were implemented in the schools.

The null hypothesis tested states, "There is neither a significant difference in the school heads' mean rating scores on the extent of implementation of the policy guidelines on parental involvement in decision making in ward schools in Rukwa region based on education level and work experience nor interaction between the two independent variables". The model was used because it tested the interaction of independent variables, besides measuring main effects of each independent variable (Brase and Brase, 1999, Field, 2013). The same ANOVA assumptions and their checking applied in this hypothesis test. However, the test of the assumption of equality of variance was not met in this test. The test results are summarized in Table 3.

\begin{tabular}{|c|c|c|c|c|c|c|}
\hline \multicolumn{7}{|c|}{ Tests of Between-Subjects Effects } \\
\hline Source & $\begin{array}{c}\text { Type III Sum of } \\
\text { Squares }\end{array}$ & $\mathrm{df}$ & Mean Square & $\mathrm{F}$ & Sig. & $\begin{array}{c}\text { Partial Eta } \\
\text { Squared }\end{array}$ \\
\hline Corrected Model & $14.614^{\mathrm{a}}$ & 4 & 3.654 & 4.129 & .012 & .418 \\
\hline Intercept & 107.847 & 1 & 107.847 & 121.892 & .000 & .841 \\
\hline Experience & 5.199 & 1 & 5.199 & 5.876 & .024 & .203 \\
\hline Education & 11.061 & 2 & 5.531 & 6.251 & .007 & .352 \\
\hline experience* & 2.601 & 1 & 2.601 & 2.940 & .100 & .113 \\
\hline
\end{tabular}




\begin{tabular}{|c|c|c|c|c|c|c|}
\hline education & & & & & & \\
\hline Error & 20.350 & 23 & .885 & & & \\
\hline Total & 151.000 & 28 & & & & \\
\hline Corrected Total & 34.964 & 27 & & & & \\
\hline
\end{tabular}

Table 3: Results of Hypothesis Testing (Two Way ANOVA)

The findings in Table 3 revealed that there was a significant main effect of work experience on the mean rating scores of heads of schools on the extent of the implementation of policy guidelines on parental involvement in decision making in ward schools in Rukwa region, $F(1,23)=5.88 ; p=.024$. There was a significant main effect of education level on the mean rating scores of heads of schools on the extent of the implementation of policy guidelines on parental involvement in decision making in ward schools in Rukwa region, $\mathrm{F}(2,23)=6.25 ; \mathrm{p}=.007$.

These results imply that education level and work experience had significant influence on the school's heads' rating scores on the extent of the implementation of the policy guidelines in relation to parents' involvement in the schools. The results further showed that there was no significant interaction between education level and work experience on the school heads' mean rating scores on the extent of implementation of the policy guidelines on parental involvement, $\mathrm{F}(1,23)=2.94, \mathrm{p}=.10$. This $\mathrm{p}$ value of .10 is greater than the significant level of .05 . Therefore, the researcher failed to reject the null hypothesis and concluded that there was no significant combined effect of education level and work experience on the mean rating scores of heads of schools on the extent of the implementation of policy guidelines on parental involvement in decision making in ward schools in Rukwa region.

The findings mean that, when combined together, the two variables of education level and work experience (in combination), had no significant influence on the mean rating scores of heads of schools on the extent of policy implementation. Each variable had an independent significant influence on participants' rating mean scores; neither of the two variables influenced the other.

Though the assumption of equality of variances was not met as per significant result, $p=.04$, (Levene's Test of Equality of Error Variancesa), the results are still accurate in this strong model of analysis of variance (Kahn and Best, 2006, p.406) after satisfying two basic assumptions of independence and normality (Marczyk; DeMatteo and Festinger, 2005, P.227) and for the large enough " $F$ " ratios (Field, 2013, p. 444).

\subsection{Hypothesis Testing 3}

The researcher was interested to find out whether there were significant differences in the mean scores of teachers on parents' participation in decision making in the schools. The hypothesis that was tested states: "There is no significant difference in the mean scores of teachers on parents' participation in decision making in ward schools in Rukwa region when compared with rural and municipal areas". Data were generated by a yes $(=2)$ and no $(=1)$ measurement. The t-test (independent sample t-test)was used because it was the appropriate model for comparing the mean scores of two independent groups (Field, 2013, p.430) that was applicable in our case.

\subsubsection{The Assumptions Of T-Test Model Are}

That the subjects in two groups are randomly and independently selected; the variances of the dependent variables of the two samples are equal (homogeneous); the distribution of dependent variable is approximately normal; the scores in the two samples are either interval or ratio. These apply to all the t-test models in this study. The assumptions of homogeneity of variance and normality in distributions were checked. The test was computed by SPSS. Table 4 presents a summary of the findings. 


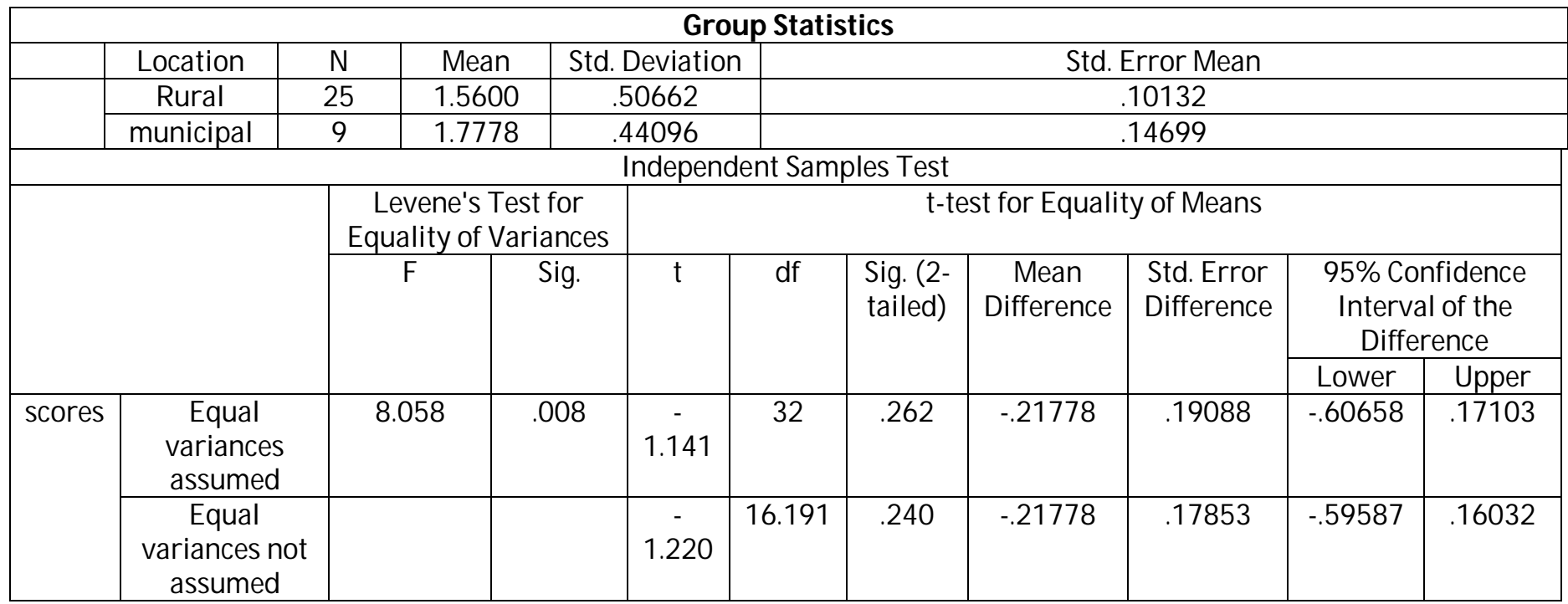

Table 4: Results of Independent Samples T - Test of Rural and Municipal Teachers' Scores

The independent samples $t$ - test results in Table 4 indicate that the mean scores of the rural group of teachers $(\mathrm{M}=$ $1.56, \mathrm{SD}=.51)$ was slightly different from those of the municipal group $(\mathrm{M}=1.78 ; \mathrm{SD}=.44)$. The results indicated $\mathrm{t}(32)=-$ $1.141, \mathrm{p}=.262$. The findings indicate that $\mathrm{p}$ value of .262 is greater than .05 value of significance level. The null hypothesis was, therefore, not rejected and the researcher concluded that there was no significant difference in the mean scores of teachers on parents' participation in decision making in ward schools in Rukwa region when compared with rural and municipal areas. Though the assumption of Equality of Variances (Levene's Test) was not met (.008), the findings were considered accurate and so reliable after satisfying the two basic assumptions of independence and normality, which make this model robust (Marczyk; DeMatteo and Festinger, 2005) and for the interval or ratio scale (Oppenheim, 1992 in Cohen et al. 2011) and which are stronger than non-parametric tests (Gray, 2004).

The findings imply that school location had no significant influence on teachers' scores on parents' participation in decision making in the schools. This implies that the rural and the municipal parents were similar in the level of their involvement as per the teachers' experience. There was no significant influence of town and rural features on parental involvement in the schools. The teachers' responses on this test corresponded to those of heads of schools in the previous One-Way ANOVA test.

The decisions made in the schools had no full legitimacy in view of the fees free basic education policy due to low level of parental participation in the schools. Low level parental involvement in the decisions means also low level of legitimacy as the policy required parents to participate in all major decisions and resolutions made in the schools. The heads of schools had partial ownership of the policy due to the top-down approach of some government officials in the implementation of the policy. It follows, therefore, that accountability in the schools diminished due to lack of parents' adequate stake in decision making and lack of ownership of the policy by the heads of schools.

Much as the education theories and practices on policy implementation on parental involvement are not adequately applied, then it becomes a matter of urgency to address this challenge and make the region cope with education management theories, principles, standards and normal practices. Therefore, the policy might not produce desired results of educational effectiveness and efficiency as gauged by legitimization of decisions and resolutions made in the schools and for ensuring accountability therein. It follows, therefore, that achieving the government's objective of provision of quality and universal fees free basic education in Rukwa region is not assured as long as these factors are not decisively addressed.

\section{Conclusions and Recommendations}

Based on the findings, the study drew the following conclusions. The policy guidelines on parental involvement in decision making in Rukwa region were inadequately implemented as not all school leaders complied with the provisions. The adherence to the policy guidelines on parental involvement in the fees free education policy in the region, did not commensurate with the expected levels as there was a mismatch between the desired and the achieved levels of parental involvement in ward schools in Rukwa region. Thus, the decisions made in the schools had no full legitimacy in view of the fees free basic education policy due to low level of parental participation therein. Low level parental participation in decision making meant also low level of legitimacy as the policy required parents to participate in all major decisions and resolutions in the schools for ensuring rightfulness of the decisions. It follows, therefore, that accountability in the schools was diminished due to lack of parents' adequate stake in making the decisions.

School location had no significant influence on the mean rating scores of school heads on the extent of the implementation of the policy guidelines on involving parents in the schools. Their education level and work experience had significant main effects on the scores. Nevertheless, the two independent variables had no significant interaction (significant combined effects) on the scores of the heads of schools on the extent of policy implementation. The school location did not significantly influence the teachers' mean scores on parents' participation in decision making in ward 
schools in Rukwa region. This implies that the participants had more or less similar experiences of parents' involvement in the schools.

Based on the findings, the study recommends that concerted efforts be made by the government with all the other education stakeholders to create more awareness among parents and to mobilize them to support the running of the schools in accordance with the policy guidelines for effective implementation of the fees free basic education policy and bring about desired education results in Rukwa region. The government is advised to make sure that parents are responsible with their children's education. This can include formulation of some laws for enforcing parental involvement.

The areas in the policy guidelines that are not clear to the parents and heads of schools, that include payments for examinations and sports and games, among others, be elaborated clearly by the government and communicated to parents, schools' management and other education stakeholders in Rukwa region. This could include widening parents' stake in the school governing boards, the official decision-making organs in the institutions.

Education management professionalism of clear communication, chain of command and proper delegation of responsibilities be adhered to and political interference in education be avoided. The school management teams be allowed to initiate voluntary contributions in schools and convince parents to take part actively and not to leave it solely to parents in the region. This section of the policy guidelines be revisited and improved by the government to accommodate parents' and local community variables, lest the region persistently lag behind in education.

The heads of schools need to practice participatory decision making to provide room for parents to play their part in the running of the institutions. They should be transparent, open and inviting to parents to scale up parents' involvement in the running of the schools. Proper and regular communication between schools and parents be ensured to make parents support them. The heads of schools also should focus on mobilizing parents to win their support as part of the strategy of ensuring an effective supportive system.

The teachers need to ensure that they create positive interaction with parents to restore or establish trust from parents and attract parental support to schools. They could involve parents more in students' management, planning for income generating projects, and provide regular and clear reports to parents. The community around the schools should also establish mutual relationships with parents. This entails holding frequent meetings with the parents in the schools and diversification of communication between the schools and the parents.

\section{References}

i. Albez, C. and Ada, S. (2017). School administrators' skills in organizing the parent participation studies, Journal of Education and Training Studies, 5(4), 165 - 175. Retrieved from: https:/ / doi.org/ 10.11114/ jets.v5i4.2184

ii. Bell, L. and Bush, T. eds. (2002). The Principles and Practice of Educational Management, London: SAGE Publications Inc.

iii. Bernard, E.G. (2004). Perceived relevance of school boards in school improvement and leadership effectiveness in Musoma district council. (Masters Dissertation): UDSM

iv. Best, J.W. and Kahn, J.V. (2006). Research in Education (10th Ed.), Boston: Pearson Education, Inc.

v. Brase, C. H. and Brase, C.P. (1999). Understandable Statistics: Concepts and Methods (6th Ed.) Boston: Houghton Mifflin Company

vi. Burilo, LJ. (2014). Community participation in quality education improvement in ward secondary schools in Temeke municipality. (Masters Dissertation): UDSM

vii. Chawe, M. (2017, July 15). Serikali yakemea upotoshaji elimu bure [The government rebukes misrepresentation of free education], Habarileo, p.4

viii. Creswell, J.W. (2014). Research Design: Qualitative, Quantitative, and Mixed Methods Approaches. (4th Ed). Los Angeles: SAGE Publications, Ltd.

ix. Dwyer, D.J. and Hecht, J. B. (1992). Causes underlying minimal parental involvement in the education of their children (an update). School Community Journal, 2(2), 275 - 288. http:/ / www.adi.org/ journal/ ss01/ chapters/ Chapter20-Dwyer\&Hecht.pdf

x. Epstein J. L. (1995). School, Family and Community Partnerships: Caring for the Children we share. Phi Delta Kappan, 76(9), 701 - 712

xi. Fanuel, G. (2015). Parents' involvement in promoting students' academic performance in secondary schools in Same District, Tanzania. (Masters Dissertation): Mwenge Catholic University (MWECAU)

xii. Field, A. (2013). Discovering Statistics using SPSS (4th Ed.), Los Angeles: SAGE Publications Ltd

xiii. Focus, S. (2010). Internal efficiency of community secondary schools in Maswa district. (Masters Dissertation): UDSM

xiv. Gray, D.E. (2004). Doing research in the real world. London: SAGE Publications Ltd

xv. Hakielimu (2017). Impact of the implementation of fee-free education policy on basic education in Tanzania: A qualitative study. Research report: Da es Salaam

xvi. Heystek, J. (2011). Governing bodies in South African Schools: Under pressure to enhance democratization and improve quality, Educational Management Administration \& Leadership, 39(4), 455-468. DOI: $10.1177 / 1741143211406149$

xvii. Hoover-Dempsey, K. and Sandler, H. (1997). Why do parents become involved in their children education? Review of Education Research, 67(1), 3 - 42. DOI: 10.2307/ 1170618

xviii. Ismail, B. (2017, January, 27). Wazazi, Walezi waweka ngumu mchango wa chakula shuleni [Parents, guardians resist contribution for food in schools]; Mwananchi News Paper, Local News, p.8 
xix. Kabir, A. H. and Akter, F. (2014). Parental involvement in the secondary schools in Bangladesh: Challenges and the way forward. International Journal of whole schooling, $10(1), 1$ - 8 . https:/ / files.eric.ed.gov/ fulltext/ EJ1030575.pdf

xx. Kakulu, S. B. (2014). Causes, magnitude and education measures of teachers' attrition in community secondary schools in SumbawangaDistrict, Tanzania. (Masters Dissertation): UDSM

xxi. Kalolo, F.J. (2016). Craving for quality education in Tanzania: Dispelling the myths. Journal of Education Issues, 2(1), 57 - 69. DOI:10.5296/ jei.v2i1. 8506

xxii. Kapela, C. (2012,). The role of school boards in managing school funds. The case of selected public secondary schools in Mbozi district. (Masters Dissertation): UDSM

xxiii. Kapinga, O. (2016). Assessment of school facilities in the context of free basic education in Tanzania: A paper presented at the quality education conference at Seashells Hotel Millennium Tower, Dar es Salaam

xxiv. Kisembe, W. and Were, S. (2014).Challenges affecting implementation of strategic planning in management of secondary schools in Kiambu County. International Journal of Social Sciences Management and Entrepreneurship $1(2), 121-140$

xxv. Lawuo, E. A.; Machumu, H. J.; and Kimaro, A. R. (2015)Uncovered coping strategies adopted by children living in homeswith marital conflicts for their own survivalJournal of Education and Practice,6(18), 114 - 129. https:/ / files.eric.ed.gov/ fulltext/ EJ1079722.pdf

xxvi. Maendaenda, T. (2010). Causes and patterns of dropouts in community secondary schools: A case study of Korogwe town council, Republic of Tanzania. (Masters Dissertation): UDSM

xxvii. Magava, OJ. (2015). Constraints on the successful implementation of the universal and compulsory primary education policies in Tanzania, 1967 - 2013. (PhD Education Dissertation): UDSM

xxviii. Mahmoud, S. (2018). Saudi parents' perceptions of the kind of help they offer to their primary school kids. English Language Teaching, 11(3), 102 - 112. DOI: 10.5539/ elt.v11n3p102

xxix. Makenya, M. H. (2013). Levels of parental involvement in public secondary school's management in Moshi municipality. Unpublished (Masters Dissertation): MWECAU

xxx. Makwinya, N.M and Komba, S.C. (2014). Community - school partnership in Tanzania: The Role of parents' perceptions regarding communication and democracy in the partnership. Journal of Education; 2 (12), 1 - 14. https:/ / www.researchgate.net/ publication/ 270583551

xxxi. Mapako, F.P.; Mareva, R. and Chindeza, W. (2013). A comparison of Zimbabwe's rural and urban primary school pupils' views about homework. A case of Masvingo district. International Journal of Educational Administration and Policy Studies, 5(6), 102 - 109

xxxii. Marczyk G.; DeMatteo. D.; and Festinger, D. (2005). Essentials of Research Design and Methodology New Jersey: John Wiley \& Sons, Inc

xxxiii. Masue, O.S. (2014). Empowerment of school committees and parents in Tanzania: Delineating existence of opportunity, its use and impact on school decisions. (PhD Dissertation): University of Bergen. Retrieved from http:/ / citeseerx.ist.psu.edu/ viewdoc/ download?doi=10.1.1.841.2866\&rep=rep1\&type=pdf

xxxiv. Matekere, Y.M. (2003). Effectiveness of community secondary schools in Tanzania. A Case of Mvomero district. (Masters Dissertation): UDSM

xxxv. Mbazi, S. (2015). Effectiveness of educational decentralization by devolution for curriculum implementation in public secondary schools in Moshi rural district, Tanzania, (Masters Dissertation): MWECAU

xxxvi. McNeal, R.B. (2014). Parent involvement, academic achievement and the role of student attitudes and behaviours as mediators, Universal Journal of Educational Research, 2(8), 564 - 576. DOI; 10.13189/ ujer.2014.020805

xxxvii. Mhegera, I.E. (2011). Sumbawanga ward secondary schools report. Retrieved from mhegeraelias.blogspot.com/ 2011/ 12/ Sumbawanga-ward-secondary-schools-report.html Retrieved on $22 / 06 / 2017$

xxxviii. Mshani, G. (2015). Poverty indicators affecting academic performance in Tanzania secondary schools at Nkasi district, (Masters Dissertation): OUT

xxxix. Mualuko, N.J and Limukii, K.E. (2012). The free education policy in Kenya: A critique; International Journal of Education Administration and Policy Studies, 4 (1), 1-5. DOI: 10.5897/ IJAPS10.031

xl. Mulwa, D. M.; Kimosop, M. K.; and Kasivu, G. M. (2015). Participatory governance in secondary schools: Students' view point in eastern region of Kenya. Journal of Education and Practice, 6(30), 59 - 64. https:/ / files.eric.ed.gov/ fulltext/ EJ1081338.pdf

xli. Mufuruki, A. A.; Mawji, R; Kasiga, G. and Marwa, M. (2017). Tanzania's Industrialization Journey, 2016 2056:From an Agrarian to Modern Industrialized State in Forty Years. Nairobi: Moran (E.A.) Publishers Limited

xlii. Ndasi, A. K. (2003). Factors affecting secondary school administration in Sumbawanga District, Tanzania. (Masters Dissertation): Catholic University of Eastern Africa

xliii. Ngalawa, A.; Simmt, E. and Glanfield, F. (2015). Exploring the emergence of community support for school and encouragement of innovation for improving rural school performance: Lessons learned at Kitamburo in Tanzania. Global Education Review, 2 (4). 101 - 119. https:/ / files.eric.ed.gov/ fulltext/ EJ1080909.pdf

xliv. Ngigi, K, F, (2014), Influence of parental involvement in the implementation of curriculum in public primary schools in Ndeiya, Kiambu County, Kenya. (Masters Dissertation): University of Nairobi. Retrieved from http:/ / eap.uonbi.ac.ke/ sites/ default/ files/ cees/ education/ eap/ MASTER\%20FINAL\%20PROJECT.pdf 
xlv. Nudzor,H.P.(2013) Exploring the policy implementation paradox: using the Free Compulsory Universal Basic Education (fCUBE) policy in Ghana as an exemplar, International Journal of Qualitative Studies26(多). DOI: 10.1080/ 09518398.2012.705043

xlvi. Nyandwi, D.M. (2014). Determinants of poor academic performance of secondary school students in Sumbawanga district, Tanzania, (Maters Dissertation): Sokoine University of Agriculture (SUA)

xlvii. Okeke, C.I. (2014). Effective home - school partnership: Some strategies to help strengthen parental involvement, South African Journal of Education, 34(3), $1-8$ of the articles. http:/ / sajournalofeducation.co.za/ index.php/ saje/ article/ viewFile/ 864/ 445

xlviii. Okumbe, J. A. (1998). Educational Management: Theory and Practice, Nairobi: Nairobi University Press

xlix. Olayiwola, S. and Alabi, K. (2015). The Micro-politics of school principals' decision making in Nigeria. International Journal of Educational Leadership and Management, 3(2), 173 - 191. DOI: 10.17583/ ijelm.2015.1441

l. Oyeniran, R. (2017). Basic education in Ivory Coast: From education for all to compulsory education; Challenges and perspectives. Journal of Education and Learning; 6(2), 283 - 29. DOI: 10.5539/ jel.v6n2p283

li. Pansiri, N.O. \& Bulawa, P. (2013). Parents' participation in public primary schools in Botswana: Perceptions and experiences of head teachers". International Education Studies, 6(5), 68 - 76. DOI:10.5539/ ies.v6n5p69

lii. Peiffer, G.D. (2015). The Effect of self-efficacy on parental involvement at the secondary school level. PhD Dissertation, University of Pittsburgh. Retrieved from http://dscholarship.pitt.edu/ 25252/ 1/ DissertationGaryPeifferREV5-11 \%281\%29 MND Edits \%281\%29 Updated1.pdf

liii. Prater, D.; Bermudez, A.B and Owens E. (1997). Examining parental involvement in rural, urban and suburban schools. Journal of Research in Rural Education, 13(1), 72 - 75. http://jrre.vmhost.psu.edu/ wpcontent/ uploads/ 2014/ 02/ 13-1_8.pdf

liv. Rajabu, H. (2011). The role of parents' associations in improving the academic performance of public secondary schools in Tanzania. (Masters Dissertation): UDSM

lv. Rapp, N. and Duncan, H. (2012). Multi-Dimensional parental involvement in schools: A Principal's guide" International Journal of Educational Leadership Preparation, vol. 7(1), 1 - 14. https:/ / files.eric.ed.gov/ fulltext/ EJ971515.pdf

lvi. Salema, V. (2009).An Evaluation of the implementation of secondary school development program in government -community secondary schools in Rombo District, Kilimanjaro - Tanzania. (Masters Dissertation): Catholic University of Eastern Africa (CUEA)

lvii. Siyame, P. (2016, January, 15). Rukwa RC orders all parents who fail to send their children to school traced. Daily news, Local news, p.2

lviii. Siyame, P. (2016, January, 25). Parents refuse to pay for meals. Daily news, p.2

lix. Siyame, P. (2016, December 1). 10,800 selected to join form one. Habarileo, p.2

lx. Sumarsono, R.B; Imron, A; Wiyano, B.B. and Arifin, I. (2016). Parents' participation in improving the quality of elementary school in the city of Malang, East Java, Indonesia. International Education Studies, 9(10), 256 - 262. DOI: $10.5539 /$ ies.v9n10p256

lxi. Tesha, P.S. (2012). Analysis of the role of school leadership in promoting academic and social development of the school in Meru community. Focus on governmentsecondary schools. (Masters Dissertation): UDSM

lxii. THAKERS LIMTED (1965, February 1). Bidii ya TAPA (TAPA's effort), Ngurumo, p.2

lxiii. Thungu, J., Wandera, K., Gachie, L. \& Alumande, G. (2010). Mastering PTE Education Nairobi: Oxford University Press

lxiv. URT (2014). Basic Education Statistics in Tanzania (BEST), Dar es Salaam: MoEVT

lxv. URT (2014). Education and Training Policy, Dar es Salaam: MoEVT

lxvi. URT (2015). Secondary School Management Toolkit (SSMT), Practical Guide for Heads of Schools: MoEVT

lxvii. URT (2015). Waraka elimu namba 6 wa mwaka 2015 kuhusu utekelezaji wa elimu msingi bila malipo [Education circular number 6 of 2015 on implementing fees free basic education] Dar es salaam: MoEVT

lxviii. URT (2016). Basic Education Statistics in Tanzania (BEST), Dar es Salaam: MoEST

lxix. URT (2016). Waraka wa elimu namba 3 wa mwaka 2016 kuhusu utekelezaji wa elimumsingi bila malipo [Education circular number 3 of 2016 on implementing fees free basic education].Ministry of Education, Science and Technology (MoEST)

lxx. URT (2016, February 29). Utaratibu wa utoajiwa wa vibali vya kuchangia kwa hiari mahitaji kwa ajili ya kutatua kero zilizopo shuleni [Procedure for granting permits for voluntary contributions for allaying challenges in schools]. Dodoma: Tawala za Mikoa na Serikali za Mitaa (TAMISEMI)

lxxi. Yassin, I. (2017, January 31). A Teacher caned for punishing a student. Tanzania Daima,News, p. 2

lxxii. Zahara, A. (2014). Factors hindering effective parental involvement in children's schooling in public primary schools in Kinondoni municipality, Tanzania. (Masters Dissertation): UDSM

lxxiii. Zedan, R. F. (2012). Parents' involvement among the Arab ethnic minority in the State of Israel, School Community Journal, 2(2), 161-182.

lxxiv. https:/ / files.eric.ed.gov/ fulltext/ EJ1001617.pdf 